\title{
IMPLEMENTASI AKAD JU'ALAH DALAM LEMBAGA KEUANGAN SYARIAH
}

\author{
Afriani $^{1}$, Ahmad Saepudin ${ }^{2}$ \\ ${ }^{I}$ Mahasiswa Prodi Ekonomi Syariah Pascasarjana UIN SGD Bandung \\ ${ }^{2}$ Dosen Prodi Perbankan Syariah STIES Indonesia Purwakarta \\ 1 ahmadsaepudin988@yahoo.com \\ 2 afriani@bjbs.co.id
}

\begin{abstract}
Intisari- Jualah adalah sejenis sebuah ungkapan janji yang diucapkan oleh seseorang yang kehilangan sesuatu barangnya yang hilang dengan memberikan sejenis hadiah kepada orang yang menemukannya,dengan memberi batasan-batasan tetentu. Hal biasanya dilakukan untuk hal-hal yang dianggap sangat penting. Masalah Konsep ju'alah yang kebanyakan orang pahami hampir sama dengan konsep ijarah sehingga dalam memahami suatu perbuatan mu'amalah kadang berbeda paham. Nah untuk lebih jelasnya apa yang dimaksud dengan ju'alah? jualah atau jialah, berasal dari bahasa arab: ja'ala-yaj'alu-ja'lan. Ja'ala secara harfiah bermakna mengadakan atau menjadikan, sedangkan Ju'alah bermakna upah, harga atau gaji. Dalam kehidupan sehari -hari sering kita jumpai ada seseorang yang kehilangan anaknya, karena anak tersebut amat sangat penting bagi orang tuanya sehingga orang tua yang kehilangan tersebut mengadakan sebuah sayembara, barang siapa yang dapat menemukannya maka akan di beri hadiah dengan ketentuan yang telah ditetapkan oleh. Dalam hal ini penulis akan mencoba membahas pembiyaan akad ju'alah pengertian secara etimologi berarti upah atau hadiah yang diberikan kepada seseorang karena orang tersebut mengerjakan atau melaksanakan suatu pekerjaan tertentu. Secara terminologi fiqih berarti "suatu Iltizaam (tanggung jawab) dalam bentuk janji memberikan imbalan upah tertentu secara sukarela terhadap orang yang berhasil melakukan perbuatan atau memberikan jasa yang belum pasti dapat dilaksanakan atau dihasilkan sesuai dengan yang diharapkan.
\end{abstract}

Kata kunci- Akad Ju'alah.

Abstract - Jualah is a kind of a promise expressed by someone who lost something of his lost item by giving some kind of reward to the one who found it, with certain limitations. Things are usually done for things that are considered very important. Ju'alah concept that most people understand almost the same as the concept of ijarah so that in understanding an act mu'amalah sometimes different understand. Well for more details what is meant by ju'alah? Jualah or jialah, derived from Arabic: ja'ala-yaj'alu-ja'lan. Ja'ala is literally meaningful to make or make, while Ju'alah means wage, price or salary. Everyday life we often encounter someone who lost his son, because the child is very very important for his parents so that the lost parents are holding a contest, who can find it will be given a gift with the conditions set by. In this case the author. Will try to discuss the justification agreement meaning etymology means wages or rewards given to someone because the person is doing or performing a particular job. The terminology of fiqih means "an Iltizaam (responsibility) in the form of a promise to give a certain voluntary wage reward against a person who successfully performs an act or provides an uncertain service can be executed or produced as expected.

Keywords - Akad Ju'alah.

\section{PENDAhuluaN}

Islam sebagai ad-din mengandung ajaran yang komprehensif dan sempurna(syumul ). Islam mengatur seluruh aspek kehidupan manusia, tidak saja aspek ibadah, tetapi juga aspek muamalah, khususnya ekonomi Islam. Al- Qur'an secara tegas menyatakan kesempurnaan Islam tersebut dalam banyak ayat, antara lain Kesempurnaan Islam itu tidak saja diakui oleh intelektual muslim, tetapi juga para orientalist barat, di antaranya H.A.R Gibb yang mengatakan, "Islam is much more than a system of theology it's a complete civilization."

Salah satu ajaran Islam yang mengatur kehidupan manusia adalah aspek ekonomi (mua'malah, iqtishodiyah ). Ajaran Islam tentang ekonomi cukup banyak, baik dalam Al-quran, Sunnah, maupun ijtihad para ulama. Hal ini menunjukkan bahwa perhatian Islam dalam masalah ekonomi sangat besar. Ayat yang terpanjang dalam Al-Quran justru berisi tentang masalah perekonomian, bukan masalah ibadah (mahdhah) atau aqidah. Ayat yang terpanjang itu ialah ayat 282 dalam surah Albaqarah, yang menurut Ibnu Arabi ayat ini mengandung 52 hukum/malasah ekonomi).
Dalam pembahasan kali ini saya akan membahas tentang jialah, jialah ini merupakan pemberian upah (hadiah) atas suatu manfaat yang diduga bakal terwujud, seperti mempersyaratkan kesembuhan dari seorang dokter, atau kepandaian dari seorang guru, atau pencari/penemu hamba yang lari. Jialah ini juga dapat dijadikan sebagai akad.

\section{PEMBAHASAN}

\section{A. Pengertian Ju'alah}

Pengupahan (ju'alah) menurut bahasa ialah apa yang diberikan kepada seseorang karena sesuatu yang dikerjakannya, sedangkan pengupahan (ju'alah) menurut syariah, Al-Jazairi (2005:525-526) menyebutkan hadiah atau pemberian seseorang dalam jumlah tertentu kepada orang yang mengerjakan perbuatan khusus, diketahui atau tidak diketahui. Misalnya, seseorang bisa berkata," Barangsiapa membangun tembok ini untukku, ia berhak mendapatkan uang sekian”. Maka, orang yang membangun tembok untuknya berhak atas hadiah(upah) yang ia sediakan, banyak atau sedikit. Istilah lain dalam pengupahan adalah ijarah. Penggunaan kedua istilah ini sesuai dengan teks dan konteksnya. ${ }^{1}$ 
$J$ 'alah adalah meminta agar mengembalikan barang yang hilang dengan bayaran yang ditentukan. Misalnya, seseorang kehilangan kuda, dia berkata,"Barang siapa yang mendapatkan kudaku dan dia kembalikan kepadaku, aku bayar sekian". ${ }^{2} \mathrm{Al}-$ ju'l ialah pemberian upah (hadiah) atas suatu manfaat yang diduga bakal terwujud, seperti mempersyaratkan kesembuhan dari seorang dokter, atau kepandaian dari seorang guru, atau pencari/ penemu hamba yang lari. ${ }^{3}$

Kata jialah secara bahasa artinya mengupah. Secara syara' sebagaimana dikemukakan oleh Sayyid Sabiq : "sebuah akad untuk mendapatkan materi (upah) yang diduga kuat dapat diperoleh". Istilah jualah dalam kehidupan sehari-hari diartikan oleh fukaha yaitu memberi upah kepada orang lain yang dapat menemukan barangnya yang hilang atau mengobati orang yang sakit atau menggali sumur sampai memancarkan air atau seseorang menang dalam sebuah kompetisi. Jadi, jialah bukan hanya terbatas pada barang yang hilang namun dapat setiap pekerjaan yang dapat menguntungkan seseorang. ${ }^{4}$

Dalam buku Ensiklopedi Hukum Islam ji'alah berarti upah atau hadiah yang diberikan kepada seseorang karena orang tersebut mengerjakan atau melaksanakan suatu pekerjaan atau perbuatan tertentu. ${ }^{5}$ Meskipun ji'alah berbentuk upah atau hadiah sebagaimana ditegaskanoleh Ibnu Qudamah, ulama Mazhab Hanbali, ia dapat dibedakan dengan Ijarah dari lima segi.

Pertama, pada ji'alah upah atau hadiah yang dijanjikan hanya boleh diterima oleh orang yang menyatakan sanggup untuk mewujudkan apa yang menjadi objek pekerjaan atau perbuatan tersebut, jika pekerjaan atau perbuatan tersebut telah mewujudkan hasil dengan sempurna. Sedangkan pada ijarah, orang yang melaksanakan pekerjaan tersebut berhak menerima upah sesuai dengan ukuran atau kadar prestasi yang telah diberikannya meskipun pekerjaan itu belum sempurna dilaksanakannya.

Kedua, pada ji'alah terdapat unsur gharar (penipuan, spekulasi, untunguntungan) karena di dalamnya terdapat ketidaktegasan dari segi batas waktu penyelesaian pekerjaan ataupun cara dan bentuk penyelesaian pekerjaannya. Sedangkan dalam ijarah, batas waktu penyelesaian, bentuk pekerjaan, dan cara kerjanya disebutkan secara tegas dalam perjanjian, sehingga orang yang melaksanakan pekerjaan dalam ijarah harus mengerjakan pekerjaan yang dijadikan objek perjanjian sesuai dengan batas waktu dan bentuk pekerjaan yang disebutkan dalam transaksi. Dengan kata lain, yang dipentingkan dalam ju'alah adalah keberhasilan pekerjaan, bukan batas waktu penyelesaian ataupun bentuk atau cara mengerjakannya.

Ketiga, pada ji'alah tidak dibenarkan adanya pemberian imbalan upah atau hadiah sebelum pekerjaan dilaksanakan. Sedangkan dalam ijarah, pemberian upah terlebih dahulu dibenarkan, baik secara keseluruhan ataupun sebagian, baik sebelum pekerjaan dilaksanakan maupun ketika pekerjaan sedang berlangsung.

Keempat, tindakan hukum yang dilakukan dalam ji'alah bersifat sukarela. Sehingga apa yang dijanjikan boleh saja dibatalkan (fasakh) selama pekerjaan belum dimulai tanpa menimbulkan akibat hukum, sedangkan ijarah merupakan transaksi yang bersifat mengikat semua pihak yang melakukan

${ }^{2}$ H. Sulaiman Rasjid, Fiqh Islam(Bandung: Sinar BAru Algesindo,2008) hlm. 305 .

${ }^{3}$ Ibnu Rusyd, Bidayatul Mujtahid analisis fiqih para mujtahid (Jakarta: Pustaka Amani, 2007), hlm.101. perjanjian kerja. Dengan demikian, jika perjanjian tersebut dibatalkan, maka tindakan itu menimbulkan akibat hukum bagi pihak bersangkutan, salah satu pihak yang melakukan perjanjian ijarah dapat mengajukan tuntutan ganti rugi kepada pihak yang lain jika perjanjian ijarah tersebut dibatalkan.

Kelima, dari segi ruang lingkupnya, Mazhab Maliki menetapkan kaidah bahwa semua yang dibenarkan menjadi objek dalam transaksi ji'alah boleh menjadi objek dalam transaksi ijarah, tetapi tidak semua yang dibenarkan menjadi objek dalam transaksi ijarah dibenarkan pula menjadi objek dalam transaksi ji'alah. dengan kata lain, ruang lingkup ijarah lebih luas dari pada ruang lingkup ji'alah.

Berdasarkan kaidah tersebut maka pekerjaan menggali sumur sampai menemukan air, atau menjadi pembantu rumah tangga selama sebulan misalnya, dapat menjadi objek dalam transaksi ijarah., tetapi tidak menjadi objek dalam transaksi ji'alah. Kedua contoh perbuatan tersebut tidak sah menjadi objek transaksi ji'alah karena pihak yang menjanjikan upah pekerjaan tersebut telah mendapatkan manfaat dari kedua pekerjaan tersebut meskipun sumur yang digali tidak sampai menemukan air, atau meskipun pembantu rumah tangga itu belum cukup sebulan bekerja, padahal pihak yang melakukan pekerjaan tersebut tidak berhak menerima hadiah atau upah sebelum pekerjaan tersebut dilaksanakannya dengan sempurna.

\section{B. Rukun dan Syarat Jialah}

Rukun pengupahan (ju'alah) adalah sebagai berikut: ${ }^{6}$

1. Lafal (akad). Lafal itu mengandung arti izin kepada yang akan bekerja dan tidak ditentukan waktunya. Jika mengerjakan jialah tanpa seizin orang yang menyuruh (punya barang) maka baginya tidak berhak memperoleh imbalan jika barang itu ditemukan. Ada 2 orang yang berakad dalam jialah yaitu :

a. Ja'il yaitu orang yang mengadakan sayembara. Disyaratkan bagi ja'il itu orang yang mukallaf dalam arti baligh, berakal, dan cerdas

b. 'Amil adalah orang yang melakukan sayembara. Tidak disyaratkan 'amil itu orang-orang tertentu (bebas).

2. Orang yang menjanjikan memberikan upah. Dapat berupa orang yang kehilangan barang atau orang lain.

3. Pekerjaan (sesuatu yang disyaratkan oleh orang yang memiliki harta dalam sayembara tersebut).

4. Upah harus jelas, telah ditentukan dan diketahui oleh seseorang sebelum melaksanakan pekerjaan (menemukan barang).

\section{Syarat Jialah}

1. Pihak-pihak yang berji'alah wajib memiliki kecakapan bermu'amalah (ahliyyah al-tasharruf), yaitu berakal, baligh, dan rasyid (tidak sedang dalam perwalian). Jadi ji'alah tidak sah dilakukan oleh orang gila atau anak kecil.

2. upah (ja'il) yang dijanjikan harus disebutkan secara jelas jumlahnya. Jika upahnya tidak jelas, maka akad ji'alah batal adanya, karena ketidak pastian kompensasi. Seperti, barang siapa yang menemukan mobil saya yang hilang, maka ia berhak mendapatkan baju. Selain itu, upah yang diperjanjikan itu bukanlah barang haram, seperti

${ }^{4}$ H. Abdul Rahman Ghazaly, Fiqh Muamalah (Jakarta: Kencana Prenada Media Grup, 2010), hlm.141. syariah.html,

http://www.perencana.info/2013/03/sistem-nisbah-bagi-hasil-bank-

${ }^{6}$ H. Abdul Rahman Ghazaly, Fiqh Muamalah, hlm. 143. 
minuman keras.

3. Aktivitas yang akan diberi kompensasi wajib aktivitas yang mubah, bukan yang haram dan diperbolehkan secara syar'i. Tidak diperbolehkan menyewa tenaga paranormal untuk mengeluarkan jin, praktek sihir, atau praktek haram lainnya. Kaidahnya adalah, setiap asset yang boleh dijadikan sebagai obyek transaksi dalam akad ji'alah

4. Kompensasi (materi) yang diberikan harus jelas diketahui jenis dan jumlahnya (ma'lum), di samping tentunya harus halal. $^{7}$

Kalau orang yang kehilangan itu berseru kepada masyarakat umum," Siapa yang memndapatkan barangku akan ku beri uang sekian,". Kemudian dua orang bekerja mencari barang itu, sampai keduanya mendapatkan barang itu bersama-sama, maka upah yang dijanjikan tadi berserikat antara keduanya.

\section{Landasan Hukum}

a. Al-Quran Surat An-Nisa ayat 58

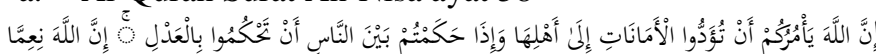

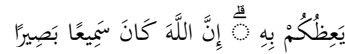

Sesungguhnya Allah menyuruh kamu menyampaikan amanat kepada yang berhak menerimanya, dan (menyuruh kamu) apabila menetapkan hukum di antara manusia supaya kamu menetapkan dengan adil. Sesungguhnya Allah memberi pengajaran yang sebaik-baiknya kepadamu. Sesungguhnya Allah adalah Maha Mendengar lagi Maha Melihat.

b. QS Yusuf 72

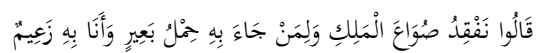

Penyeru-penyeru itu berkata: "Kami kehilangan piala raja; dan siapa yang dapat mengembalikannya, akan memperoleh bahan makanan (seberat) beban unta, dan aku menjamin terhadapnya" (QS. Yusuf: 72)

c. Hadis-hadis Nabi shallallahu alaihi wasallam tentang beberapa prinsip bermu'amalah, antara lain:

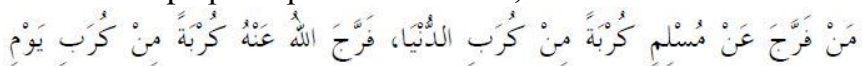

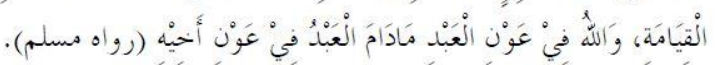

"Barang siapa melepaskan dari seorang muslim suatu kesulitan di dunia, Allah akan melepaskan kesulitan darinya pada hari kiamat; dan Allah senantiasa menolong hamba-Nya selama ia (suka) menolong saudaranya" (HR. Muslim dari Abu Hurairah).

d. HR. Tirmidzi dari 'Amr bin 'Auf

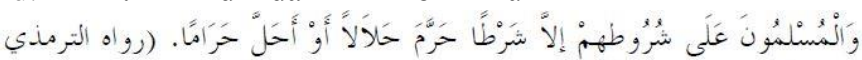

$$
\begin{aligned}
& \text { عن عمرو بن عوف) }
\end{aligned}
$$

"Kaum muslimin terikat dengan syarat-syarat yang mereka buat kecuali syarat yang mengharamkan yang halal atau menghalalkan yang haram." (HR. Tirmidzi dari 'Amr bin 'Auf) e. QS

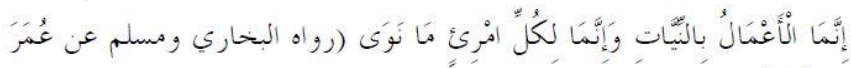

$$
\begin{aligned}
& \text { بْن ألْخطَّاب) }
\end{aligned}
$$

"Setiap amalan itu hanyalah tergantung pada niatnya. Dan seseorang akan mendapat ganjaran sesuai dengan apa yang diniatkannya." (HR. Bukhari \& Muslim dari Umar bin Khattab) f. Hadis riwayat Imam al-Bukhari dari Abu Sa'id al-Khudri



"Sekelompok sahabat Nabi SAW melintasi salah satu kampung orang Arab. Penduduk kampung tersebut tidak menghidangkan makanan kepada mereka. Ketika itu, kepala kampung disengat kalajengking. Mereka lalu bertanya kepada para sahabat: 'Apakah kalian mempunyai obat, atau adakah yang dapat me-ruqyah (menjampi)?' Para sahabat menjawab:

'Kalian tidak menjamu kami; kami tidak mau mengobati kecuali kalian memberi imbalan kepada kami.' Kemudian para penduduk berjanji akan memberikan sejumlah ekor kambing. Seorang sahabat membacakan surat al-Fatihah dan mengumpulkan ludah, lalu ludah itu ia semprotkan ke kepala kampung tersebut; ia pun sembuh. Mereka kemudian menyerahkan kambing. Para sahabat berkata, 'Kita tidak boleh mengambil kambing ini sampai kita bertanya kepada Nabi SAW.' Selanjutnya mereka bertanya kepada beliau. Beliau tertawa dan bersabda, 'Lho, kalian kok tahu bahwa surat alFatihah adalah ruqyah! Ambillah kambing tersebut dan berilah saya bagian."' (HR. Bukhari).

g. Pendapat Ibnu Qudamah dalam al-Mughni, VIII/323

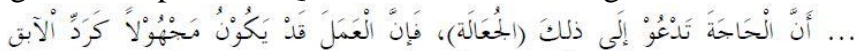

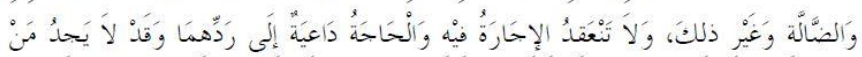



"Kebutuhan masyarakat memerlukan adanya ju'alah; sebab pekerjaan (untuk mencapai suatu tujuan) terkadang tidak jelas (bentuk dan masa pelaksanaannya), seperti mengembalikan budak yang hilang, hewan hilang, dan sebagainya. Untuk pekerjaan seperti ini tidak sah dilakukan akad ijarah (sewa/pengupahan) padahal (orang/pemiliknya) perlu agar kedua barang yang hilang tersebut kembali, sementara itu, ia tidak menemukan orang yang mau membantu mengembalikannya secara suka rela (tanpa imbalan). Oleh karena itu, kebutuhan masyarakat mendorong agar akad ju'alah untuk keperluan seperti itu dibolehkan sekalipun (bentuk dan masa pelaksanaan) pekerjaan tersebut tidak jelas."

h. Pendapat Imam al-Nawawi dalam al-Majmu' Syarh alMuhadzdzab, XV/449:

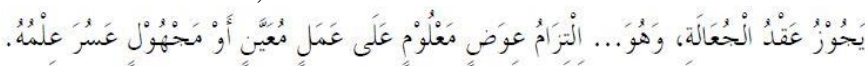

"Boleh melakukan akad Ju'alah, yaitu komitmen (seseorang) untuk memberikan imbalan tertentu atas pekerjaan tertentu atau tidak tertentu yang sulit diketahui."

i. Pendapat para ulama dalam kitab Hasyiyah al-Bajuri II/24

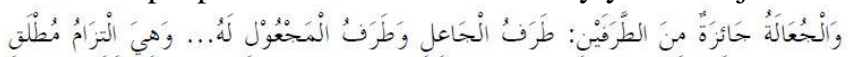

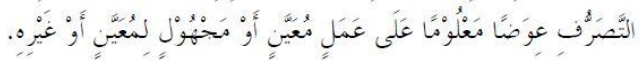

“Ju'alah boleh dilakukan oleh dua pihak, pihak ja'il (pihak pertama yang menyatakan kesediaan memberikan imbalan atas suatu pekerjaan) dan pihak maj'ul lah (pihak kedua yang bersedia melakukan pekerjaan yang diperlukan pihak pertama)..., (Ju'alah) adalah komitmen orang yang cakap hukum untuk memberikan imbalan tertentu atas pekerjaan 


\section{tertentu atau tidak tertentu kepada orang tertentu atau tidak tertentu.}

Kedudukan transaksi upah (al-ju'l) adalah segala bekerja bentuk pekerjaan (jasa), yang pemberi upah tidak mengambil sedikitpun dari upah (hadiah) itu. Sebab, jika pemberi upah mengambil sebagian dari upah itu, berarti ia harus terikat dengan jasa dan pekerjaan itu. Padahal jika calon penerima upah itu (al-maj'ul) gagal mendatangkan manfaat, seperti ditetapkan dalam transaksi upah (al-ju'l), ia tidak akan mendapatkan apa-apa. Jika pemberi upah (al-ja'il) mengambil hasil kerja calon penerima upah (al-maj'ul), tanpa imbalan kerja atau jasa tertentu, berarti ia telah melakukan suatu kezaliman. ${ }^{8}$

\section{E. Operasional Hukum Ju'alah}

Pelaksanaan dalam system pengupahan menurut Al-Jazairi di antaranya mengandung hukum-hukum pengupahan (ju'alah) yaitu sebagai berikut ${ }^{9}$ :

1. Pengupahan (ju'alah) adalah akad yang diperbolehkan. Kedua belah pihak yang bertransaksi dalam pengupahan diperbolehkan membatalkannya. Jika pembetalan terjadi sebelum pekerjaan dimulai maka pekerja tidak mendapatkan apa-apa. Jika pembatalan terjadi di tengahtengah proses pekerjaan maka pekerja berhak mendapatkan upah atas pekerjaan.

2. Dalam pengupahan (ju'alah), masa pengerjaan tidak disyaratkan diketahui. Jika seseorang berkata,' Barangsiapa bisa menemukan untaku yang hilang, ia akan mendapatkan hadiah satu dinar". Orang yang berhasil menemukannya berhak atas hadiah tersebut walaupun menemukannya setelah sebulan atau setahun.

3. Jika pengerjaan dilakukan sejumlah orang maka upah atau hadiahnya dibagi secara merata antara mereka.

4. Pengupahan (ju'alah) tidak boleh pada hal-hal yang diharamkan. Jadi, seseorang tidak boleh berkata,'Barang siapa menyakiti atau memukuli si Fulan atau memakinya, ia mendapatkan upah (ju'alah) sekian”.

5. Barang siapa menemukan barang tercecer atau barang hilang atau mengerjakan suatu pekerjaan dan sebelumnya ia tidak mengetahui kalua di dalamnya terdapat upah (ju'alah), ia tidak berhak atas upah tersebut kendati ia telah menemukan barang yang tercecer tersebut, karena perbuatannya itu ia lakukan secara suka rela sejak awal. Jadi, ia tidak berhak mendapatkan ju'alah tersebut kecuali jika ia berhasil menemukan budak yang melarikan diri dari tuannya, sebagai balas budi atas perbuatannya tersebut.

6. Jika seseorang berkata,"Barang siapa makan dan minum sesuatu yang dihalalkan, ia berhak atas upah(ju'alah),' maka ju'alah seperti itu diperbolehkan, kecuali jika ia berkata,"Baranng siapa makan dan tidak memakan sesuatu daripadanya, ia berhak atas ju'alah," ju'alah seperti ini tidak sah.

7. Jika pemilik ju'alah dan pekerja tidak sependapat tentang besarnya ju'alahmaka ucapan yang diterima adalahucapan pemilik ju'alah dengan disuruh bersumpah.jika kedua berbeda pendapat tentang pokok ju'alah maka ucapan yang diterima ialah ucapan pekerja

${ }^{8}$ Ibnu Rusyd, Bidayatul Mujtahid analisis fiqih para mujtahid (Jakarta: Pustaka Amani, 2007), hlm.102.

${ }^{9}$ H. Ismail Nawawi, Fikih Muamalah Klasik dan Kontemporer (Bogor: Galia Indonesia, 2012), hlm.192. dengan disuruh bersumpah.

\section{F. Pelaksanaan Jialah}

Teknis pelaksanaan jialah dapat dilakukan dengan dua cara, yaitu :

1. Ditentukan oleh orangnya.

Misalnya : si Andia dengan sendirinya mencari barang yang hilang.

2. Secara umum, artinya orang yang diberi pekerjaan mencari barang bukan satu orang, tetapi bersifat umum yaitu siapa saja.

Misalnya : seseorang berkata "Siapa saja yang dapat mengembalikan barangku yang hilang maka akan aku beri upah sekian".

\section{G. Pembatalan Jialah}

Madzab Malikiyah menyatakan, akad ji'alah boleh dibatalkan ketika pekerjaan belum dilaksanakan oleh pekerja ('amil). Sedangkan menurut Syafi'iyah dan Hanabilah, akad ji'alah boleh dibatalkan kapanpun, sebagaimana akad-akad lain, seperti syirkah dan wakalah, sebelum pekerjaan diselesaikan secara sempurna. Jika akad dibatalkan di awal, atau di tengah berlangsungnya kontrak, maka hal itu tidak masalah, karena tujuan akad belum tercapai. Jika akad dibatalkan setelah dilaksanakannya pekerjaan, maka 'amil boleh mendapatkan upah sesuai yang dikerjakan.

Pembatalan jialah dapat dilakukan oleh kedua belah pihak (orang yang kehilangan barang dengan orang yang dijanjikan jialah atau orang yang mencari barang) sebelum bekerja. Jika pembatalan datang dari orang yang bekerja mencari barang, maka ia tidak mendapatkan upah sekalipun ia telah bekerja. Tetapi, jika yang membatalkannya itu pihak yang menjanjikan upah maka yang bekerja berhak menuntut upah sebanyak pekerjaan yang telah dilakukan. ${ }^{10}$

\section{H. Aplikasi Pada Perbankan}

Aplikasinya ialah pada SBIS (sertifikat Bank Indonesia Syariah). Peraturan Bank Indonesia (PBI) No. 10/11/PBI/2008 tentang Sertifikat Bank Indonesia Syariah (SBIS)(“PBI 10/11/2008”).SBIS adalah adalah surat berharga berdasarkan Prinsip Syariah berjangka waktu pendek dalam mata uang rupiah yang diterbitkan oleh Bank Indonesia (Pasal 1 angka 4 PBI 10/11/2008). SBIS yang diterbitkan oleh Bank Indonesia menggunakan akad Ju'alah (Akad ju'alah adalah janji atau komitmen (iltizam) untuk memberikan imbalan tertentu ('iwadh/ju'l) atas pencapaian hasil (natijah) yang ditentukan dari suatu pekerjaan). Sesuai dengan FATWA DEWAN SYARI'AH NASIONAL NO: 64/DSNMUI/XII/2007 tentang SERTIFIKAT BANK INDONESIA SYARIAH JU'ALAH ( SBIS JU'ALAH ) menetapkan bahwa Sertifikat Bank Indonesia Syariah Ju'alah (SBIS Ju'alah) adalah SBIS yang menggunakan Akad Ju'alah, dengan memperhatikan substansi fatwa DSN-MUI no. 62/DSNMUI/XII/2007 tentang Akad Ju'alah. Dalam SBIS Ju'alah, Bank Indonesia bertindak sebagai ja'il(pemberi pekerjaan); Bank Syariah bertindak sebagai maj'ullah (penerima pekerjaan); dan objek/underlying Ju'alah(mahall al'aqd) adalah partisipasi Bank Syariah untuk membantu tugas Bank Indonesia dalam pengendalian moneter melalui penyerapan likuiditas dari masyarakat dan menempatkannya di Bank Indonesia dalam jumlah dan jangka waktu tertentu

${ }^{10}$ H. Abdul Rahman Ghazaly, Fiqh Muamalah (Jakarta: Kencana Prenada Media Grup, 2010), hlm.143. 
EKSISBANK Vol. 2 No. 1 Desember 2018

\section{KESIMPULAN}

1. Pengupahan (ju'alah) menurut bahasa ialah apa yang diberikan kepada seseorang karena sesuatu yang dikerjakannya, sedangkan pengupahan (ju'alah) menurut syariah, Al-Jazairi (2005:525-526) menyebutkan hadiah atau pemberian seseorang dalam jumlah tertentu kepada orang yang mengerjakan perbuatan khusus, diketahui atau tidak diketahui. Misalnya, seseorang bisa berkata," Barangsiapa membangun tembok ini untukku, ia berhak mendapatkan uang sekian". Maka, orang yang membangun tembok untuknya berhak atas hadiah(upah) yang ia sediakan, banyak atau sedikit. Istilah lain dalam pengupahan adalah ijarah. Penggunaan kedua istilah ini sesuai dengan teks dan konteksnya.

2. Rukun dan syarat pengupahan (ju'alah) adalah sebagai berikut:

a. Lafal (akad). Lafal itu mengandung arti izin kepada yang akan bekerja dan tidak ditentukan waktunya. Jika mengerjakan jialah tanpa seizin orang yang menyuruh (punya barang) maka baginya tidak berhak memperoleh imbalan jika barang itu ditemukan.

b. Orang yang menjanjikan memberikan upah.

c. Pekerjaan (sesuatu yang disyaratkan oleh orang yang memiliki harta dalam sayembara tersebut).

d. Upah harus jelas,

3. Dalam al-Qur'an dengan tegas Allah membolehkan memberikan upah kepada orang lain yang telah berjasa menemukan barang yang hilang. Hal itu ditegaskan dalam al-Qur'an surat Yusuf ayat 72 .

4. Aplikasinya ialah pada SBIS (sertifikat Bank Indonesia Syariah). Peraturan Bank Indonesia (PBI) No. 10/11/PBI/2008 tentang Sertifikat Bank Indonesia Syariah (SBIS)(“PBI 10/11/2008”).

\section{REFERENSI}

[1] Ghazaly,H. Abdul Rahman, Fiqh Muamalah,Jakarta: Kencana Prenada Media Grup, 2010

[2] Nawawi, H. Ismail, Fikih Muamalah Klasik dan Kontemporer, Bogor: Galia Indonesia, 2012.

[3] Rasjid, H. Sulaiman, Fiqh Islam, Bandung: Sinar Baru Algesindo,2008

[4] Rusyd,Ibnu, Bidayatul Mujtahid analisis fiqih para mujtahid, Jakarta Pustaka Amani, 2007.

[5] http://www.perencana.info/2013/03/sistem-nisbah-bagi-hasil-banksyariah.html, 